\title{
A Grounded Theory Analysis of the Occupational Impact of Caring for a Partner who has Multiple Sclerosis
}

\author{
Kate Heward, Matthew Molineux \& Brendan Gough
}

\begin{abstract}
Chronic progressive conditions such as multiple sclerosis impact engagement in and orchestration of daily occupations by people with the condition, and their family members. This qualitative study addressed the way in which multiple sclerosis can affect family life, particularly exploring how it affects the occupations of the partner of a person with the condition. The study involved in-depth interviewing and grounded theory analysis to explore the occupational nature of being a partner of someone who has multiple sclerosis. Findings reveal how partners' occupations are affected over time, with occupational opportunities inspired by multiple sclerosis and occupational constraints provoked by the disorder, including nostalgia for an multiple sclerosis free existence, the transition to being a carer and an occupationally uncertain future.
\end{abstract}

Key Words
Occupation
Multiple sclerosis
Carers
Caregiving

Kate Heward BSc(HONS) O.T. is a PhD student at Leeds Metropolitan University, Leeds, United Kingdom. She is also a senior lecturer at Sheffield Hallam University.

Dr Matthew Molineux is Head of Occupational Science and Occupational Therapy, School of Allied Health Professions, at Leeds Metropolitan University, Leeds, UK.

Dr Brendan Gough is a Senior Lecturer in Qualitative Psychology, University of Leeds, Leeds, UK.

Address for correspondence:

k.heward@shu.ac.uk
Multiple sclerosis is the most common disease of the central nervous system affecting young adults in the United Kingdom. Although the epidemiology of the disorder and the experience of people diagnosed with it have been researched, there has been little focus on carer, partner or family perspectives. This article reports a qualitative study, which addressed the question: "What are the occupational issues for partners of people with multiple sclerosis?"

This question is important because there are an estimated $2,500,000$ people in the world living with multiple sclerosis, approximately 85,000 of whom live in the United Kingdom. Living with somebody who has been diagnosed with multiple sclerosis often leads to providing care. Almost six million people in Britain are carers (Department of Health, 1999), defined here as "a family member or paid helper who regularly looks after a sick, elderly or disabled person" (Soanes \& Stevenson, 2004, p. 213). The nature of the care provided is shaped by the health condition. With multiple sclerosis, twice as many women are diagnosed with the disease as men (Multiple Sclerosis Trust, 2004). The condition is usually progressive and while four general patterns have been identified, individual experience varies and cannot be predicted (Finlayson, van Denend, \& DalMonte, 2005; Lindsay \& Bone, 2004). The unpredictability of the condition is one of the most anxiety provoking issues for those diagnosed with the condition and those closest to them (Monks, 1990; Robinson, Jones \& Segal, 1990; Silcox, 2003).

Diagnosis of multiple sclerosis is often a very lengthy process whereby people undergo numerous investigations and experience months, and sometimes years of concerning symptoms before a clear diagnosis is made (Monks, 1990; Silcox, 2003). The condition is complex, featuring a range of physical symptoms including loss of mobility, spasticity, loss of bladder control, visual disturbances, fatigue, cognitive problems such as memory loss, and associated psychological issues such as depression and adjustment to change (Lindsay \& Bone, 2004; Silcox). There is no known cure and so treatments aim to relieve symptoms, slow the progression of the disease and manage its impact (Lindsay \& Bone; Silcox). Individuals diagnosed with multiple sclerosis can live for many years with the condition (Weinshenker, 1995) and may experience many of the symptoms highlighted or relatively few depending on whether they are have a progressive or relapsing remitting form of the condition (Buljevac et al., 2003).

Multiple sclerosis has the potential to affect the whole family, 
including their general lifestyle (Cheung \& Hocking, 2004). It is often diagnosed at a time when critical life decisions are being made in terms of furthering careers, establishing longterm relationships, or having children (Aronson, Goldenberg, \& Cleghorn, 1996; Grima et al., 2000; Nolan \& Nolan, 1998). It therefore has the potential to disrupt established, evolving and future occupations.

Carers' perspectives are high on the British government's agenda, and have been embedded in key documents such as the National Health Service Plan (DoH, 2002), the Carers and Disabled Child Act (DoH, 2000a), and the Social Services National Inspection Report: A Matter of Chance for Carers (Fruni, 1998). The National Service Framework for Older People (DoH, 2000b) has also highlighted that carers should be consulted about their views and needs. The recently published National Service Framework for Longer Term Conditions (DoH, 2005), including multiple sclerosis, has been informed by carer perspectives and recognises their needs both as carers and in their own right.

\section{The Occupational Impact of Multiple Sclerosis: Emerging Research Findings}

A number of studies have focussed on the occupational performance of people diagnosed with multiple sclerosis (Finlayson, Van Denend, \& DalMonte, 2005; Jackson \& Quaal, 1991), with a few highlighting the wider occupational experience of individuals with the disorder. Wright-St. Clair (2003) found that women with multiple sclerosis experience it metaphorically, as an "adversary", "guest", "aggressor" or "saviour", which enables them to somehow survive with the condition. Similarly, Finlay (2003) described how one woman renegotiated the relationship between mind and body, whilst she learned to live with the diagnosis. These insights align with earlier work that stressed the importance of story telling, in that it helps people take positive control over the disease (Robinson, I., 1990).

A small number of studies have focussed on the caregivers of people with multiple sclerosis (McKeown, Porter-Armstrong, $\&$ Baxter, 2003). Amongst these, some have identified the various coping strategies that spouses, partners or other family members use when caring for somebody with multiple sclerosis. These include problem-based strategies such as planning, and emotional strategies such as temporary emotional or physical withdrawal in order to cope with the caring role (Gulick, 1995). Others have alluded to changes in relationships and socialisation (Esgate, 1995), and people with multiple sclerosis can feel their condition will inhibit sexual relationships as the caring role increases (Silcox, 2003). A more recent qualitative study of the experiences of 'spousal carers' of people with multiple sclerosis identified a number of paradoxes that captured the participants' positive and negative experiences, such as feeling both enabled and limited through caring (Cheung \& Hocking, 2004).

Whilst carers do not experience multiple sclerosis physically, they often experience it emotionally and practically in their everyday life (Ohman \& Soderberg, 2004). One study identified specific occupational impacts multiple sclerosis may have on carers, including the negative financial impact of being forced to give up work or change their planned career development to accommodate increasing care duties (Esgate, 1995). While this study did not identify the nature of the caring relationship, partners frequently become carers of people with disabilities. As multiple sclerosis is most commonly diagnosed when people are at the peak of their working lives and often at a time when they are in or considering serious relationships or families, this disorder may have a significant impact on the partner of the person diagnosed (Ohman \& Soderberg, 2004; Pakenham, 2005).

These findings are important because the positive links between meaningful occupation and health are welldocumented (Clark, 1993; Jackson, Carlson, Mandel, Zemke, \& Clark, 1998; Wilcock, 1998a, 1998b; Yerxa, 1998). In line with such perspectives, United Kingdom government policies have outlined that carers have a right to their own lives $(\mathrm{DoH}$, 2005). Accordingly, the aim of this study was to investigate the occupational issues for partners of people with multiple sclerosis. Partners were chosen as the focus because they are likely to have a significantly different relationship with the person with multiple sclerosis than other family members or friends and because the caring role may extend over many years, unless the strain becomes too much as the caring role increases (Chipchase \& Lincoln, 2001). Therefore, we were keen to identify what occupational issues arise when facing a chronic health condition, and whether there is any disruption to partners' occupational choices, participation and meaning.

\section{Method}

Although qualitative studies are usually more time consuming and expensive than quantitative inquiries (Hancock, 2000), their strength is in the depth of information obtained from small numbers of participants (Smith, 2004; Willig, 2001). Qualitative methods also allow the flexibility to develop the methods as the research evolves (Belgrave, Zablotsky, \& Guadagno, 2002; Denzin \& Lincoln, 1994). Since this study sought to elicit participants' perspectives, we were interested in the depth and richness of information rather than its generalisibility.

The chosen methodology was constructionist grounded theory, which recognises the prior knowledge and creativity of the researcher (Strauss \& Corbin, 1990). In particular, we used a social constructionist version of grounded theory introduced by Charmaz (1990), which suggests categories and theories do not emerge from the theory but are constructed by the researcher, through interaction with the data. The constructionist approach to grounded theory analysis recognises and accepts that researchers bring their own experiences to the research, which presents opportunities for enriching rather than biasing analysis (Charmaz, 1990; Strauss \& Corbin, 1998).

Data were collected via in-depth individual semi-structured 
interviews (Laliberte-Rudman \& Moll, 2001) conducted by the first author. Data were analysed using grounded theory methods (Charmaz, 1990; Strauss \& Corbin, 1998), which are designed to facilitate the process of discovery or generation of theories (Charmaz, 1990; Strauss \& Corbin, 1998).

We chose to use interviewing because it allows detailed exploration of participants' views and it is an established method of data collection within qualitative research (Willig, 2001) including grounded theory (Charmaz, 2000). An interview schedule was constructed, informed by the literature (Creswell, 1998; Laliberte-Rudman \& Moll, 2001). The aims of the study also highlighted topic areas for the interview, as did the clinical experience of the occupational therapists in the research team. The interviewer guided participants through their past, present, and future, identifying their occupational engagement at different stages. Examples of questions asked in relation to shared occupations and the relationship of health and occupation are listed in Table 1.

\section{Table 1. Example Questions from the Interview Schedule}

\section{Question}

Probe

Have the things you do together changed over the years?

How is your health currently?

How do you see the future?
- How have they changed?

- How does it feel (to carry out the same occupations/different ones)?

- How much time do you spend on these occupations, is that more or less time than you used to?

- How would you feel if you couldn't carry out the occupations your partner's multiple sclerosis?

- How much do you think the changes have been due to multiple sclerosis, and how much do you put down to natural life changes?

- What in your opinion contributes to your well-being?

- Is this related to multiple sclerosis in your opinion?

- What are the things you do that you believe affect your health in both a positive and negative way?

- What do you think would improve your health occupationally? (Taking part in new occupations, rediscovering old ones)

- Do you make plans? (Elaborate)

- Are they independent of your partner? With your partner? you enjoy anymore because of

\section{Participants}

It is not possible to precisely determine the number of participants prior to a study (Whalley Hammell, 2002) and this is especially true when using grounded theory (Charmaz, 1990; Strauss \& Corbin, 1998). Once the appropriate university ethics committee granted approval for the study, nine partners of people with multiple sclerosis were interviewed, all heterosexual and married. This number is typical for interview based qualitative research where saturation of themes often occurs between 6-10 participants, when core themes have been identified and validated (Smith, 1995).

Purposive sampling (Bogdan \& Bilken, 1992) was used, with the selection criteria as presented in Table 2. The participants accepted into the study came from a variety of sources and backgrounds in the North of England: one was a work colleague, one was the friend of a work colleague, three were through a local multiple sclerosis group, one was through another participant and three were recruited via the Multiple Sclerosis Society newsletter. Table 3 describes the participants.

\section{Data collection and analysis}

A pilot interview was successfully carried out, and the information it generated was included in the analysis. No major changes were made to the interview schedule. All participants were given the choice of where they wanted to be interviewed, as long as it was in a quiet environment and their partner would not be present. Prior to commencing the interview, participants were informed about the project and invited to sign the consent form if they agreed to take part.

Analysis of the data ran concurrently with the data collection, which is typical of a grounded theory study (Whalley Hammell, 2002; Willig, 2001). Each interview was coded lineby-line and clustering was used to develop themes. There were initially a vast number of descriptive themes, but through constant comparative analysis (Strauss \& Corbin, 1998) they were developed into fewer analytical themes. A journal was maintained by the primary researcher to capture ongoing reflections and observations (Valliant Cook, 2001). Reflections were recorded immediately after interviews, relating to the non-verbal communication of the participant and emotions witnessed during the interview. Other reflections arose as the transcriptions were analysed in relation to phrases the participants may have used and thoughts that were evoked by them.

\section{Trustworthiness}

Credibility is crucial to all research and so strategies were instituted to ensure trustworthiness, validity, quality and rigour. The second and third authors listened to tape recordings and read transcripts, and analysis was carried out independently on a sample of the transcripts by all authors of the paper (Charmaz, 1990; Lincoln \& Guba, 1985; Pidgeon \& Henwood, 1997).

Member checking was initiated approximately two months post interview, to allow time to carry out in-depth analysis of the transcripts (Willig, 2001). Contact was made with each of the participants to clarify interpretations of the transcripts and it was found that participants endorsed the analysis. 
Table 2. Participant Criteria

\begin{tabular}{lll}
\hline Inclusion Criteria & Exclusion Criteria & Rationale \\
\hline $\begin{array}{l}\text { Relapsing/remitting or secondary } \\
\text { progressive multiple sclerosis }\end{array}$ & $\begin{array}{l}\text { Benign or primary progressive multiple } \\
\text { sclerosis }\end{array}$ & $\begin{array}{l}\text { A greater percentage of the multiple } \\
\text { sclerosis population will have relapsing } \\
\text { remitting or secondary progressive } \\
\text { multiple sclerosis at any one time, } \\
\text { making recruitment to the study easier. It } \\
\text { is also more representative of the } \\
\text { multiple sclerosis population }\end{array}$
\end{tabular}

Partner to have had an intimate relationship with the individual diagnosed with multiple sclerosis before diagnosis

Partner to have no major health complaints

Partner who has not had an intimate relationship with the person diagnosed with multiple sclerosis before diagnosis

Partners who have major health complaints

Individuals who are experiencing crisis e.g., within their relationship, or in relation to their partners multiple sclerosis
Experiences can be compared before and after diagnosis

The experience of partners who have health complaints are likely to have encountered different issues to those who are well

The topic area is sensitive in nature and it would be ethically inappropriate to interview individuals who are already experiencing sensitive issues
Table 3. Description of the Participants

\begin{tabular}{|c|c|c|}
\hline Characteristic & Participant Feature & Number \\
\hline \multirow[t]{2}{*}{ Gender } & Male & 5 \\
\hline & Female & 4 \\
\hline \multirow[t]{2}{*}{ Time with partner } & Mean (years) & \\
\hline & Range (years) & $15-55$ \\
\hline \multirow{2}{*}{$\begin{array}{l}\text { Time since partner } \\
\text { diagnosed with } \\
\text { multiple sclerosis }\end{array}$} & Mean (years) & 18 \\
\hline & Range (years) & $3-40$ \\
\hline \multirow[t]{6}{*}{ Employment status } & Full time paid & 5 \\
\hline & Unemployed & 1 \\
\hline & Retired & 1 \\
\hline & Early retirement due to & \\
\hline & partners condition & 1 \\
\hline & $\begin{array}{l}\text { Given up paid employment } \\
\text { to become partner's carer }\end{array}$ & 1 \\
\hline \multirow[t]{3}{*}{ Employment type } & Healthcare & 3 \\
\hline & Education & 1 \\
\hline & Executive & 1 \\
\hline \multirow{3}{*}{$\begin{array}{l}\text { Employment status of } \\
\text { individual with } \\
\text { multiple sclerosis }\end{array}$} & Full time paid & 1 \\
\hline & Part time paid & 1 \\
\hline & Retired due to ill health & 7 \\
\hline \multirow{3}{*}{$\begin{array}{l}\text { Physical ability of } \\
\text { person with multiple } \\
\text { sclerosis (as reported } \\
\text { by partner }\end{array}$} & Mobile & 1 \\
\hline & Some mobility but & \\
\hline & Wheelchair dependent & 6 \\
\hline
\end{tabular}

\section{Findings}

Two core themes were identified; multiple sclerosis provoked occupational constraints and multiple sclerosis inspired occupational opportunities. Within the theme of multiple sclerosis provoked occupational constraints were three sub themes; nostalgia for a multiple sclerosis free existence, the transition to carer and an occupationally uncertain future.

\section{Multiple sclerosis provoked occupational constraints}

The all-encompassing reach of multiple sclerosis was very apparent in how participants perceived the future, their perceptions of the present and, for those who had lived with it for a long time, their recollections of the past. This is supported by Blair (2000), who examined transitions from an occupational perspective. She confirmed that throughout life, changes occur which require individuals to adapt and adjust what they do and how they do it. Adams, Hayes and Hopson (1976) described four different transitions of a predictable and unpredictable nature. These reflect the findings of this study in that there were predictable voluntary and involuntary life changes occurring for participants, in their relationships and employment issues, which occurred in spite of the multiple sclerosis. However, there are also the unpredictable voluntary and involuntary transitions which could be attributed to the multiple sclerosis, where again employment may be an example. In this study, these could be the same life issues as the predictable changes if a partner's condition deteriorated unexpectedly and occupational adjustments were made in the face of this. Participants in the study highlighted the ways they had made changes to their lifestyle to accommodate their partner's multiple sclerosis, or the ways that changes had been 
imposed on them, when they had been expected to adjust.

The participants described how their occupational engagement was restricted. Jennifer expressed how restricted she sometimes felt as a result of her husband having multiple sclerosis and how her husband having multiple sclerosis had influenced her recent decision to reduce her working hours:

I think the last couple of years it did get to me a bit.... I was still working full time, there was the children and the washing and the cleaning and he was doing things but it involved a lot more effort... I couldn't maintain a decent sort of quality life at work and at home and I was just feeling pulled both ways. So I've just gone for three months, sort of four days a week so I can do the boring housework (laughs) or have the energy to do the boring housework.

Their marital life was perceived as more of a partnership before the multiple sclerosis was diagnosed with equality in roles and responsibilities. After diagnosis and with progression of the condition, responsibilities were gradually shifted to Jennifer, and restrictions were imposed on her own time:

I don't mind but I would rather go and do things, I'd rather go out for the day and visit somewhere, meet people or create something.... I've just got to adjust... but I've already got a lot more done at home.

Cockerill and Warren (1990) also found that caregivers' activities had been curtailed, although these were in direct response to being able to arrange appropriate care in order for the caregiver to attend a social event or holiday. Further, the results of a systematic review of the literature emphasised that caring for someone with multiple sclerosis has a detrimental effect on many areas of a carer's life, including their social and work life (McKeown et al., 2003). The findings of our study suggest issues of occupational constraint when the roles and responsibilities have shifted so that the partner is taking on tasks that were once not theirs, rather than those specifically linked to direct care for their partner. This assumption of extra duties meant there was less time to engage in leisure occupations or paid employment.

Some participants expressed how let down they can feel when they have planned an outing which is cancelled at the last minute and they find themselves constrained to the house:

You know she gets very tired and we can arrange to go out to the cinema on a particular evening and you get home and you have your tea and you're all excited. Then all of a sudden it's, you know, I can't go because I don't feel well enough. So actually going out is a problem and planning to do something. (Jim).

Fatigue is a very disabling symptom of multiple sclerosis and even though someone might appear physically very able, their lives and those around them can become very restricted (Colosimo et al., 1995; Krupp, Alvarez, Larocca, \& Scheinberg, 1988). The uncertainty of the symptoms of multiple sclerosis and how it will affect someone in the space of days, months and years also contributes to the constraints partners can feel. Cheung and Hocking (2004) reflected these issues of uncertainty through their study, highlighting how partners were concerned about what function their partner would lose next. This study further links the inability to plan with the uncertainty of the condition:

The big thing now is that we plan for six months in advance, whereas a few years ago we would plan a year in advance. Maybe in another few years we'll only be doing 3 months. (Carol)

This statement also illustrates what Ohman and Soderberg (2004) referred to as a "shrinking life" (p. 406) in that plans become further constrained and restricted due to the erratic, fluctuating and progressive nature of multiple sclerosis.

\section{Nostalgia for a multiple sclerosis free existence}

Many of the participants described occupations they engaged in, and what those occupations meant to them, before the disruption of multiple sclerosis. They portrayed a time when they did not fear for the future and had freedom to undertake their own occupations. For those whose experience of multiple sclerosis within their lives was more recent, the nostalgia for a multiple sclerosis free existence was more powerful than for those who had lived with it for many years. Graham, whose wife had only been diagnosed with multiple sclerosis six years earlier described in detail the occupations he used to do, those he shared with his wife and what they meant to him.

We were both earning well, no family ties, life was fairly easy, we could do anything we wanted, holidays, whatever we wanted to do. We golfed, we were off to events, horse racing, whatever, a whole series of things.... It was really a matter of having fun I guess. (Graham)

Graham described the freedom they felt through the occupations they shared. However, his wife's multiple sclerosis related disabilities had advanced quickly in a short time, and although they still managed to go on holiday they had lost many of the other occupations they shared. This had resulted in the balance of leisure and productivity shifting, so more time was spent preparing meals and managing household tasks with less on leisure. He predicted further loss and changes in the future as his wife's multiple sclerosis progressed. This finding is consistent with previous reports that caregivers of people with chronic illnesses experience both loss of lifestyle and loss of relationships as they once knew them (Robinson, K., 1990). Cheung and Hocking (2004) highlighted a dearth of literature relating to grief as a response to non-death related losses (p. 154). Loss when a partner who is caring for someone with a long term condition such as multiple sclerosis is likely to exist for a number of years, whilst they are experiencing deterioration of their partner's condition. For Graham, the losses and nostalgia for a life as it was before the interruption of multiple sclerosis was magnified, as the change in both his and his wife's life have been so dramatic.

Jim experienced both isolation and alienation because his wife was not able to join him on nights out at the local pub. This was originally a male group, but as the children grew up wives of the men also attended. Jim said that because his wife rarely joined them, due to fatigue and mobility issues, he felt alienated from the group.

I find it very difficult to sit there with my wife not being 
there.... It's not so much the units of alcohol, it's the walking there and back.... On the odd occasion she does come and we walk back, my friends walk 200 yards in front at normal pace, you know we've got to slow down (sigh). I've even offered to drive...but she says... 'No'... that's difficult. (Jim)

This account reveals sorrow over a lost occupation, when there had been an attempt to re-engage and this failed, leaving Jim feeling an outcast and alienated from the group. For others the isolation became an issue when they were no longer able to go out with friends because there was nobody to look after their partner and they could not leave their partner alone.

When he is poorly my life comes to a total halt because there is no way he can be left... I just have to be there for him all the time. (Carol)

Wright St Clair (2003) described how individuals who have made their illness their focus can isolate themselves. Our research suggests that the partner can frequently be a victim of that isolation due to either their partner's incapacity, illness immersion or their inability to leave their partner for fear of the consequences.

\section{The transition to carer}

For some participants, multiple sclerosis was an intrinsic part of everyday life and the occupation of becoming a carer was accepted. Lifestyle changes followed inevitably. This had no association with how long they had lived with multiple sclerosis. Carol described her typical day as follows:

Get up in a morning, make the breakfast 'cos Harry can't do anything in the kitchen 'cos of his poor sight. So I make his cereals, whatever, bring it upstairs. I make sure all his clothes are out for him. If he's not well I tend to help him with his shower and help put his lower clothes on. He still shaves himself which he does very very slowly, but is important to him 'cos he values his independence... then I go to work. (Carol)

Acceptance was reflected in a factual way, in that it was a duty that had to be performed in order for the day to proceed for both of them. Although these may seem like the occupations of a carer, Carol did not describe herself as her husband's carer. She described carers in a detached manner, although her part in that was apparent through the duties she described. She furthermore stated how she thought resource centres for people with multiple sclerosis were a good idea so that carers could:

... do something they would like to do, just shopping,

having your hair done, just to know they (the person with multiple sclerosis) is taken care of.

This statement highlights the responsibility that is associated with being a carer but in this case, the extent to which Carol accepts a carer identity is brought into question. It may illustrate someone who is in a transient state from being a partner to being a carer. For other participants, the transition to carer was tarnished with resentment and a sense of being forced into a role they do not want to fulfil.

This word 'carer' I have problems with that. If you collect prescriptions for someone near you who is disabled you might be described as a carer; I used to do that but I wouldn't have called myself a carer. There's a difference between that and what I do now. Carer is a nice name for a slave or dogsbody. (Harold)

Harold believed he no longer had any rights in his role as a carer and could not spend the amount of time he used to do on his own occupations: "It's very hard not to sort of feel a sense of resentment". For others there was a sense of postponing the transition. Graham discussed the impositions of caring and how that could impinge on daily life:

The difficulty is if you are away, if you are late. She can't grip anything, so she can't go near a pan, she would be hurting herself. So, if I happen to get delayed at work.... I have an hour, hour and a half when I get home when I am preparing tea and having tea, and that's time taken up that wouldn't have been taken up before. (Graham)

Graham's anxieties regarding his wife's ability were apparent as were his concerns regarding his own capacity to fulfil his new roles. The urgency with which he spoke illustrated the pressure that was increasingly becoming a reality in their home life. The considerable lifestyle changes were also highlighted for a man whose career had been all encompassing, compared with his current situation where the impact of his wife's multiple sclerosis had become the most significant part of his life. These issues were accentuated by other participants who described occupations that had been imposed upon them due to their partners multiple sclerosis. Jim noted occupations that had been transferred to him as his wife has become more disabled:

Sheila is getting progressively worse with fatigue. I am taking on more of the roles of helping around the house... although she can drive, I drive everywhere... she finds it a bit too much... [I spend a lot of time] dropping the children off at school and running them around.... It was a realisation that there were things to do with the family and home that I would need to take on. (Jim)

All these issues are supported in the literature. Lackey and Gates (2001) and van Exel, van den Berg, Koopmanschap and van den Bos (2004) found caring duties can encroach adversely on other daily life activities, highlighting the burden that can ultimately arise.

\section{An occupationally uncertain future}

When looking forwards in time, participants were unable to recognise a future that was not dominated and directed by multiple sclerosis. All the participants identified being unable to make long-term plans as they were unsure of the progression of their partner's condition. Multiple sclerosis was the determinant of what would happen in the future. Some suggested practical plans that could be in place so that the occupations they shared and those they were still able to do might have a chance of being sustained. Graham described the shared occupation of holidaying in Spain, an occupation they wanted to continue but one that in the future is likely to dramatically change.

The apartment [we have] in Spain is a first floor one. It's a lovely apartment... but we have got it up for sale... If we can sell it... buy a villa we could modify, so that we can get walk in showers instead of baths, some wider doors and things, so not in the height of 
summer but in the spring and autumn when the weather's particularly nice, then just go and crash out for six weeks. (Graham)

Graham was keen to convey that he would maintain some control over the multiple sclerosis by accommodating it, so that he and his wife could continue to share holidays abroad together. Cheung and Hocking (2004) also observed that even though many spousal carers of people with multiple sclerosis may have to give up many of their chosen occupations to look after their partners, they could still continue to lead positive lives by developing ways of living with the misfortunes the condition might bring. Paradoxically Graham was postponing the future, by delaying his retirement from paid employment:

I actually retired last April, but the company asked me to cover while they got a replacement.... I'm still working full time, it's scheduled until the end of March... then they have asked me to work until June... so that's the time. (Graham)

Blair (2000) also suggested that people use 'doing' as a way of coping with prospective losses and as a way of avoiding facing the emotions of thinking about what the future might hold. Graham indicated this by establishing the importance of his position within the company as a possible excuse not to retire and thus face the future.

Cheung and Hocking's (2004) idea that partners are able to adjust to their changing circumstances were not echoed by all the participants in this study. Jim's wife Sheila is still mobile and working part time. His expectations of planning for the future are clouded by the multiple sclerosis his wife has:

I'm very mindful of the fact that if [Sheila's] progression keeps the rate it is or even slows, my quality of life when I get to retire isn't going to be very good. I am very minded that if there is anything we want to do together (travel in particular) that we ought to do it in the next few years... and just recently it's been weighing on my mind. (Jim)

Here is it apparent that Jim has ambitions that he wants to fulfil with his wife, but that the steady, albeit unpredictable progression of multiple sclerosis means that he has condemned himself to a bleak retirement. They have made no firm plans to achieve their goals, although longer-term plans in theory should be brought forward so that they can be enjoyed before the disabilities increase. However, if plans are not made, an occupationally uncertain future can have a number of consequences, as Jane expressed:

Multiple sclerosis has robbed us of our future together. Because [Geoff] is in a wheelchair I will never be able to walk down the beach or down the road holding his hand. (Jane)

\section{Multiple sclerosis inspired occupational opportunities}

HIV and AIDS have been described as a progressive medical condition that provides occupational opportunities (Bartos \& McDonald, 2000). One mechanism they describe is through people who are diagnosed with HIV literally making it a career as they seek and hold jobs within the HIV/AIDS industry. Likewise, some of the participants interviewed for this research had become involved in the multiple sclerosis community as a result of their partner being diagnosed. Jim described how his wife's diagnosis had opened new career prospects for him.

We found out about the [local] branch of the multiple sclerosis society... Later that year the firm I work for decided to adopt multiple sclerosis as the charity of the year... I became (more) involved with the society that way. We did some fundraising for the branch... I ended up joining the local committee, and becoming the newsletter editor. (Jim)

In describing his new role, Jim said he experienced "Personal satisfaction, helping people with multiple sclerosis through the work I do". This new occupation had broadened his horizons further in that he had enrolled for various college courses not related to multiple sclerosis, finding a new enthusiasm for learning and developing himself, using education as an outlet. In the trajectory of Jim's life, this would have been less of an opportunity if his wife had not been diagnosed with multiple sclerosis. When Jim described his history, he claimed his wife to have been the academic one within their relationship and the one with the motivation to succeed in her career. The opportunities that had been presented to him since his wife was diagnosed enabled him to excel at learning and find personal satisfaction. Literature supports the need for carers to look after their own health needs (McKeown et al., 2003) and for some people this might mean a new career linked to their partner's multiple sclerosis. Jim found confidence and an increase in self-esteem through undertaking college courses and taking an active role within the Multiple Sclerosis Society.

Multiple sclerosis inspired occupational opportunities did not only relate to taking on roles within societies or establishing new non-multiple sclerosis related occupations. It also was an investigative vocation for a number of participants, as evident when participants discussed the time up to and including diagnosis. Partners predicted what the illness could be, could outline symptoms, used medical language when describing the tests their partners had undergone and developed an in depth knowledge of the condition.

She lost her sight in one eye, she lost her taste, then things went blue in one eye and then it went off altogether... I have always been a bit scientific, I read books about what happens when you get multiple sclerosis and I thought she's got something like that, so I did a bit of reading and thought perhaps it is.... They did a lumbar puncture but they were a bit vague... she's had a long remission... I did a lot of reading about it. (Phil)

Although there is literature that supports this investigative focus by those diagnosed with a life threatening or long term condition (Bartos \& McDonald, 2000; Robinson, I., 1990), there was no literature available on whether this is an occupational role undertaken by those closest to the person diagnosed. Gulick (1995), however, described coping approaches used by spouses of people with multiple sclerosis, suggesting a systematic planning approach that concentrates on investigating the problem relating to multiple sclerosis and learning new ways of dealing with the problem. 
Occupational adjustment for some participants was the key to coping with occupational constraints, and creating opportunities. These individuals believed they were expected to accommodate for their loss, and adjusted accordingly. Some participants viewed this more positively than others. Phil did not view adjustment as negative, as he talked about maintenance of holidays although they were an adjustment from the types of holidays and way they travelled before his wife was diagnosed some years ago. He firstly explained how he bought a four-wheel drive vehicle: "We needed something she can climb into and roll out of' (Phil). He then went on to say how their actual holidaying style had adjusted:

She was still mobile. We still went out for weekends, we

didn't go camping as much.... (Now) instead of camping we go in chalets. We've also got a caravan, we go there a lot because she can get in and out, and we don't have to book. (Phil)

Phil highlighted that it was still possible to take part in the occupation of holidaying and even though the way they used to enjoy doing it had been lost. They had adjusted and were still able to visit similar places, but more importantly they enjoyed it and holidaying was a part of their lives that they continued to share. Two participants described adjustment that came from the transfer of occupations but led to opportunity and ultimately satisfaction.

When we had the other house Geoff always did the gardens. When we moved, I said 'They are my gardens now because you can't do them'. I get a lot of enjoyment out of my garden. I like to see it looking nice. (Jayne)

For Jayne, the opportunity of gardening has become a therapeutic outlet and had become a place where she could escape, highlighting the significance of occupation as an emotional outlet, and to maintain physical and emotional well-being.

Similarly Carol described the occupational opportunity of going to the cinema, which had arisen because her husband's eyesight was no longer good enough to read. They had therefore developed a shared occupation out of one that had been lost to him: "The pictures became a bit part for us, taking over from his books" (Carol). Cheung and Hocking (2004) also found participants in their study of spousal carers of people with multiple sclerosis became involved in jobs and hobbies that were possible within the limits of caring for someone with multiple sclerosis.

The participants were animated when they described the occupations they were able to do that were meaningful to them, whether it was ones they were either still able to do despite their partner's multiple sclerosis, or new ones they had discovered as a result of their partner's multiple sclerosis. The participants were able to make a positive link between being able to engage in occupations that were important to them, and maintaining well-being. Harold described the feeling of still being able to go mountain biking with friends and escape from home:

It's just being out in the fresh air, it's just the beautiful scenery. It's also the companionship and the fun you have with mates. It's, it just feeds a need. (Harold)
Harold's need for freedom was important to him, in that it enabled him to live within his home situation and was in drastic contrast to his statement about carers being 'slaves'. His experiences of his current life were extremes between having no life as a carer and being free and escaping. When the occupations participants found fulfilling were not possible because of their partners multiple sclerosis, life generally became more difficult and the pressures of living with multiple sclerosis more challenging.

\section{Conclusions}

This exploratory study aimed to develop an understanding of the occupational impact of multiple sclerosis for the partners of people diagnosed with the condition. Although it is recognised that relationships are dynamic and change over time, such changes are compounded when living with somebody who has multiple sclerosis. This research has highlighted that partners of people with multiple sclerosis can restore or develop new occupational pathways, as a couple or independently, and can make occupational plans for the future even in the face of an unpredictable condition.

This research has also highlighted how multiple sclerosis can bring partners occupational opportunities, either directly or indirectly linked to multiple sclerosis, which have a positive effect on their lives, through engagement in enjoyable occupations have had positive physical, psychological and emotional effects. Although this finding aligns with other authors (Clark, 1993; Jackson, 1998; Jackson et al., 1998; Wilcock \& Hocking, 2004; Yerxa et al., 1989), the importance for partners of people who have a long term chronic condition such as multiple sclerosis, and their occupational behaviours, have not been previously identified.

The results of this study point to a number of areas for future study, both in investigation of whether parallels can be drawn between partners of people with multiple sclerosis and those with other progressive conditions, and in the occupational behaviour of other family members. Areas for future study may include the occupational impact of multiple sclerosis on younger members of the family, particularly children, who are at the age of making career choices and who are also carers. It is also important to explore whether gender influences the role and occupational choices of partners of people with multiple sclerosis, and the occupational issues they experience, particularly those relating to productivity.

\section{References}

Adams, J., Hayes, J., \& Hopson, B. (1976). Transition: Understanding and managing personal change. London: Martin Robertson.

Aronson, K., Goldenberg, E., \& Cleghorn, G. (1996). Sociodemographic characteristics and health status of persons with multiple sclerosis and their caregivers. Multiple Sclerosis Management, 3(1), 6-15. 
Bartos, M., \& McDonald, K. (2000). HIV as identity, experience or career. AIDS Care 12(3), 299-306.

Belgrave, L., Zablotsky, D., \& Guadagno, M. (2002). How do we talk to each other? Writing qualitative research for quantitative readers. Qualitative Health Research, 12(10), 1427-1439.

Blair, S. E. E. (2000). The centrality of occupation during life transitions. British Journal of Occupational Therapy, 63(5), 231-237.

Bogdan, R. C., \& Bilken, S. K. (1992). Qualitative research for education: An introduction to theory and methods. Boston: Allyn \& Bacon.

Buljevac, D., Hop, C. J., Reedeker, A. C., Janssens, J. W., van der Merche, F. G. A., van Doorn, P. A., \& Hintzen, R. Q. (2003). Self reported stressful life events and exacerbations in multiple sclerosis. British Medical Journal, 327, 646-651.

Charmaz, K. (1990). Grounded theory. In J. A. Smith, R. Harre \& L. Van Langenhove (Eds.), Rethinking methods in psychology (pp. 27-49). London: Sage.

Cheung, J., \& Hocking, P. (2004). The experience of spousal carers of people with multiple sclerosis. Qualitative Health Research, 14(2), 153-166.

Chipchase, S. Y., \& Lincoln, N. B. (2001). Factors associated with carer strain in carers of people with multiple sclerosis. Disability and Rehabilitation, 23(17), 766-776.

Clark, F. (1993). Occupation embedded in a real life: Interweaving occupational science and occupational therapy. American Journal of Occupational Therapy, 47(12), 1067-1078.

Cockerill, R., \& Warren, S. (1990). Care for caregivers: The needs of family members of multiple sclerosis patients. Journal of Rehabilitation, January/February/March, 41-44.

Colosimo, C., Millefiorini, E., Grasso, M. G., Vinci, F., Fiorelli, M., Koudriavtseva, T., \& Pozzilli, C. (1995). Fatigue in multiple sclerosis associated with specific clinical features. Acta Neurology Scandinavia, 92, 353-355.

Creswell, J. (1998). Qualitative inquiry and research design. London: Sage.

Denzin, N. K., \& Lincoln, Y. S. (Ed.). (1994). Handbook of qualitative research. London: Sage.

Department of Health. (1999). Caring about carers: A national strategy for carers. Retrieved 9th August 2006 from http://www.carers.gov.uk from Publications, Policy and Guidance.

Department of Health. (2000a). Carers and Disabled Children Act. Retrieved 9th August from http://www.carers.gov.uk from Closed Consultations.
Department of Health. (2000b). National Health Service framework for older people. Retrieved 9th August 2006 from http://www.doh.gov.uk from Publications, Policy and Guidance.

Department of Health. (2002). The NHS plan. Retrieved 9th August 2006 from http://www.doh.gov.uk from Organisation, Policy and Modernisation.

Department of Health. (2005). The National Service framework for long-term conditions. Retrieved 9th August 2006 from http://www.doh.gov.uk from Policy and Guidance in Health and Social care Topics, Long Term Conditions.

Esgate, E. (1995). Multiple sclerosis in the community: A selective study. British Journal of Occupational Therapy, 58(2), 65-68.

Finlay, L. (2003). The intertwining of body, self and world: A phenomenological study of living with recently diagnosed multiple sclerosis. Journal of Phenomenological Psychology, 34(2), 157-178.

Finlayson, M., Van Denend, T., DalMonte, J. (2005). Older adults' perspectives on the positive and negative aspects of living with multiple sclerosis. British Journal of Occupational Therapy, 68(3), 117-124.

Fruni, D. (1998). Social Services Inspectorate: Inspection of local authority support for carers. Retrieved 9th August 2006 from http://www.dh.gov.uk/policyandguidelines/ socialservicesinspectorate/fs/en www.dh.gov.uk/ from Publications and Statistics.

Grima, D. T., Torrance, G. W., Francis, G., Rice, G., Rosner, A. N., \& Fortune, L. (2000). Health related quality of life consequences of multiple sclerosis. Multiple Sclerosis, 6, 91-98.

Gulick, E. (1995). Coping among spouses or significant others of persons with multiple sclerosis. Nursing Research, 44(4), 221-225

Hancock, B. (2000). An introduction to research methodology. In A. Wilson, M. Williams \& B. Hancock (Eds.), Research approaches in primary care (pp. 3-20). Abingdon, Radcliffe.

Jackson, J. (1998). The value of occupation as the core of treatment: Sandy's experience. American Journal of Occupational Therapy, 52(6), 466-473.

Jackson, J., Carlson, M., Mandel, D., Zemke, R., \& Clark, F. (1998). Occupation in lifestyle redesign: The well elderly study occupational therapy programme. American Journal of Occupational Therapy, 52(5), 326-336.

Jackson, F., \& Quaal, C. (1991). Effects of multiple sclerosis on occupational and career patterns. Axon, 16-23.

Krupp, L. B., Alvarez, L. A., Larocca, N. G., \& Scheinberg, L.G. (1988). Fatigue in multiple sclerosis. Archives of Neurology, 45, 435-437. 
Lackey, N., \& Gates, M. (2001). Adults recollections of their experiences as young caregivers of family members with chronic physical illness. Journal of Advanced Nursing, 34(3), 320-328.

Laliberte-Rudman, D., \& Moll, S. (2001). In-depth interviewing. In J. Valiant Cook (Ed.), Qualitative research in occupational therapy (pp. 24-57). Delmar: Thomson Learning.

Lincoln, Y., \& Guba, E. (1985). Naturalistic inquiry. Beverly Hills, CA, Sage.

Lindsay, K., \& Bone, I. (2004). Neurology and neurosurgery illustrated. London: Churchill Livingstone.

McKeown, L. P., Porter-Armstrong, A. P., \& Baxter, G. D. (2003). The needs and experiences of caregivers of individuals with multiple sclerosis: A systematic review. Clinical Rehabilitation, 17, 234-248.

Monks, J. (1990). Personal and social meanings of multiple sclerosis. In L. de Souza (Ed.), Multiple sclerosis; Approaches to management. London: Chapman and Hall.

Multiple Sclerosis Trust. (2004). Multiple sclerosis explained. London: multiple sclerosis Trust.

Nolan, M., \& Nolan, J. (1998). Rehabilitation in multiple sclerosis: The potential nursing contribution. British Journal of Therapy and Rehabilitation, 5(7), 370-375.

Ohman, M., \& Soderberg, S. (2004). The experiences of close relatives living with a person with serious chronic illness. Qualitative Health Research, 14(3), 396-410.

Pakenham, K. (2005). Relations between coping and positive and negative outcomes in carers of persons with multiple sclerosis (multiple sclerosis). Journal of Clinical Psychology in Medical Settings, 12(1), 25-38.

Pigeon, N., \& Henwood, K. (1997). Using grounded theory in psychological research. In N. Hayes (Ed.), Doing qualitative analysis in psychology (pp. 245-273). Hove: Psychological Press.

Robinson, I. (1990). Personal narratives, social careers and medical courses: Analysing life trajectories in autobiographies of people with multiple sclerosis. Social Science Medicine, 30(11), 1173-1186.

Robinson, K. (1990). The relationship between social skills, social support, self esteem and burden in adult caregivers. Journal of Advanced Nursing, 15, 788-795.

Robinson, I., Jones, R., \& Segal, J. (1990). Patients, their families and multiple sclerosis. In L. de Souza (Ed.), Multiple sclerosis: Approaches to management (pp. 153174). London: Chapman and Hall.

Silcox, L. (2003). Occupational therapy and multiple sclerosis. London: Whurr.

Smith, J. A. (1995). Semi structured interviewing and qualitative analysis. In J. A. Smith, R. Harre \& L. Van Langenhove (Eds.), Rethinking methods in psychology (pp. 9-26). London: Sage.
Smith, J. A. (2004). Reflecting on the development of interpretative phenomenological analysis and its contribution to qualitative research. Qualitative Research in Psychology, 1(1), 39-54.

Soanes, C., \& Stevenson, A. (2004). The concise Oxford dictionary (11th ed.). Oxford University Press.

Strauss, A. L., \& Corbin, J. (1990). Basics of qualitative research: Grounded theory procedures and techniques. London: Sage.

Strauss, A. L., \& Corbin, J. (1998). Basics of qualitative research: Techniques and procedures for developing grounded theory. London: Sage Publications.

Valiant Cook, J. (2001). Qualitative research in occupational therapy: Strategies and experiences. Delmar: Thomson Learning.

Van Exel, N. J. A., Van Den Berg, B., Koopmanschap, M. A., \& Van Den Bos, G. A. M. (2004). What really matters: An inquiry into the relative importance of dimensions of informal caregiver burden. Clinical Rehabilitation, 18, 683693.

Weinshenker, B. G. (1995). The natural history of multiple sclerosis. Neurologic Clinics of North America, 13, 119-146.

Whalley Hammell, K. (2002). Informing client-centred practice through qualitative inquiry: Evaluating the quality of qualitative research. British Journal of Occupational Therapy, 65(4), 175-184.

Wilcock, A. (1998a). Occupation for health. British Journal of Occupational Therapy 61(8), 340-345.

Wilcock, A. (1998b). Reflections on doing, being and becoming. Canadian Journal of Occupational Therapy, 65(5), 248-256.

Wilcock, A., \& Hocking, C. (2004). Occupation, population health and policy development. In M. Molineux (Ed.), Occupation for occupational therapists (pp. 219-230). London: Blackwell Publishing.

Wright-St. Clair, V. (2003). Storymaking and storytelling: Making sense of living with multiple sclerosis. Journal of Occupational Science, 10(1), 46-51.

Willig, C. (2001). Introducing qualitative research in psychology. Philadelphia: Open University Press.

Yerxa, E. (1998). Health and the human spirit for occupation. American Journal of Occupational Therapy, 52(6), 412-418.

Yerxa, E., Clark, F., Jackson, J., Parham, D., Pierce, D., Stein, C., \& Zemke, R. (1989). An introduction to occupational science: A foundation for occupational therapy in the $21 \mathrm{st}$ century. Occupational Therapy in Health Care, 6(4), 1-17. 